\title{
India-Sri Lanka: actualidad de la cuestión tamil
}

\section{Ricardo Forrester ${ }^{1}$}

\section{Contribución en la Sección Debates Internacionales}

Resumen: Sri Lanka e India tiene una relación histórica que ha atravesado diversos momentos y que durante el período colonial agregó a ella la presencia y el accionar de los británicos. El trasvase de población tamil (originario de Tamil Nadu, en India), durante la época colonial precisamente, iría encontrando la construcción de tensiones que habrían de derivar en la época contemporánea, en una guerra civil, que culminaría con la consagración de la mayoría cingalesa budista como hegemónica en la sociedad de Sri Lanka. En la actualidad, confluyen en el contexto de esta relación, la presencia de esa situación de los tamiles en la isla y sus reclamos derivados, operando en la exitosa gestión de la reciente elección parlamentaria de Tamil Nadu con respecto al gobierno central del Primer Ministro Narendra Modi y la influencia de ese estado indio sobre el norte de Sri Lanka; la dinámica y proyección de la familia Rajapaksa, en el poder en Sri Lanka, con mayoría parlamentaria y la acción del Consejo de Derechos Humanos de Naciones Unidas, que tiene la situación de Sri Lanka bajo investigación (promoción de los derechos humanos, asignación de responsabilidades en lo relativo a los crímenes durante el reciente conflicto armado, etc.), a través del trabajo de la Alta Comisionada, Michelle Bachelet, que debe expedirse en un informe sobre la misma en 18 meses. De tal confluencia parece posible prever más tensiones y dificultades de diverso orden.

La situación de los tamiles en Sri Lanka continúa siendo un tema de actualidad y atención, no sólo para ese país sino también para la India y el ámbito de las Naciones Unidas.

Durante la época colonial, los ingleses siguieron la regla de "dividir para gobernar" y, en esa época, algunos de los más ilustrados de Sri Lanka eran tamiles que estaban en Jaffna (ciudad del norte del país), incorporados como empleados y que luego accedieron a ser profesionales, lo que provocó cierto escozor en los no tamiles. Tras la independencia, los cingaleses buscaron recuperar el terreno perdido.

\footnotetext{
${ }^{1}$ Ministro. Grupo de Trabajo sobre Asia del Sur, Comité de Asuntos Asiáticos, Consejo Argentino para las Relaciones Internacionales (CARI).

Correo electrónico: archiebald51@gmail.com
} 
Dos cuestiones relevantes relacionadas con la India son: la de los tamiles de las plantaciones/tamiles de las montañas, y la cuestión de la Fuerza de Mantenimiento de Paz de la India, en tiempos del Primer Ministro indio Rajiv Gandhi. En el ínterin, los cingaleses recuperaron efectivamente el tiempo pasado, con leyes y enmiendas como la Sinhala Only $A c t$, que le dio al cingalés el carácter de lengua oficial del país. En otros ámbitos, como el de la educación, los tamiles enfrentaron obstáculos y desafíos que no tuvieron los cingaleses y, además, la religión oficial pasó a ser la budista.

Ahora bien, cuando se habla de los tamiles de las plantaciones, se alude a originarios de Tamil Nadu que, hacia el siglo XIX, fueron llevados por los británicos a Sri Lanka para sus plantaciones de café, caucho y te, en condiciones infrahumanas, llegando a ser casi un millón en la isla. Ese proceso provocó el desarraigo de los campesinos cingaleses de Kandyan Hill de sus tierras y profundizó su visión de los tamiles en términos de otredad, que se terminaría proyectando en condiciones de vulnerabilidad sin cambios para estos últimos (llyas, 2014).

Cuando el gobierno de Sri Lanka decidió quitarle la nacionalidad y el derecho a voto a los tamiles en la isla (a través de la Ley de Ciudadanía de Ceylán, de 1948), India intervino a través de su Primer Ministro Lal Bahadur Shastri, que concluiría firmando con la Primera Ministra de Sri Lanka, Sirimavo Bandaranaike, el Acuerdo sobre Personas de Origen Indio en Ceylán, en 1964, decidiendo la suerte de ese casi millón de apátridas. De ellos, medio millón fueron repatriados a la India, alrededor de 300.000 obtuvieron la nacionalidad (a través del Pacto Sirima-Gandhi, firmado en 1974 por las Primeras Ministras, Sirimavo Bandaranaike e Indira Gandhi) y el resto permaneció como apátridas.

Ahora bien, las fuerzas de paz indias enviadas a Sri Lanka, derivaron de un pedido de Junius Richard Jayewardene, Premier singalés, a Rajiv Gandhi y ello obedeció a dos elementos: el inicio de la guerra civil, cuando los Tigres de Liberación de Tamil Eelam atacaron a un convoy de soldados cingaleses, en 1983, y la Operación Liberación, que llevaron a cabo las Fuerzas Armadas de Sri Lanka contra los tamiles. Esto obligó a Rajiv Gandhi a intervenir, aunque no se cumplió con el objetivo de desarmar a los guerrilleros y dar pie a la paz. Las fuerzas se retiraron en la década del ' 90 y estas circunstancias terminaron costándole la vida al Primer Ministro Gandhi (Velupillai Prabhakaran, creador y líder de los Tigres de Liberación de Tamil Eelam, estimaba que -de ser reelecto- esas fuerzas de paz volverían a Sri Lanka, interesándole que eso no sucediera).

Durante el curso de la guerra civil, puede decirse que la actitud india hacia los tamiles de Sri Lanka buscaba minimizar los daños y maximizar los logros. Lógicamente, Gandhi, en campaña en India, no quería malquistarse con Tamil Nadu y operaba en Naciones Unidas y otros organismos, al tiempo que buscaba seguir el juego a Mahindra Rajapksa, el entonces Premier de Sri Lanka, como forma de estabilizar las fronteras, cooperar con la isla y además 
hacer una demostración de fuerza ante China y Pakistán (recordemos que Pakistán, en ese momento, había enviado a Sri Lanka asesores militares) (Devotta, 2009).

Con ese contexto dado, en el presente se dan tres elementos simultáneos, cuyo destino es difícil de prever. Ellos son: el fortalecimiento tamil en la India; la familia Rajapaksa en el poder en Sri Lanka y la Resolución del Consejo de Derechos Humanos de las Naciones Unidas sobre la situación en Sri Lanka.

Con respecto al primer elemento, la Alianza Secular Progresiva, que integra el Partido del Congreso, asestó una derrota electoral por 61 escaños a la Alianza Democrática Nacional del partido Bharatiya Janata (BJP) -gobernante en India- y lleva a M.K. Stalin como Ministro en Jefe para Tamil Nadu. $Y$ esa victoria en el sur de la India fortalece la influencia que tiene ese estado indio sobre el norte de Sri Lanka (The Economic Times, 2021).

Sobre el segundo, la familia Rajapaksa en el poder, cabe decir que Gotabaya Rajapaksa fue electo presidente de Sri Lanka en 2019, consolidándose un nepotismo; en tanto la familia Rajapaksa ocupa distintos cargos en el poder ejecutivo y/o el legislativo (su hermano menor, Basil Rajapaksa es el Ministro de Finanzas, su hermano Mahinda es Primer Ministro y también Ministro de Políticas Económicas e Implementación de Planes, su hermano Chamal es Ministro de Irrigación y actúa también en el ámbito de la defensa, su sobrino Namal es Ministro de la Juventud y Deportes, etc.) (Aljazeera, 2021); excepto la hermana menor de la familia -Preethi- y el padre, que tiene actualmente 85 años. Por si ello fuera poco, en las elecciones parlamentarias de agosto de 2020, el Partido Nacional Unido, que era el partido de oposición y contaba con 116 parlamentarios, perdió en dichas elecciones 115 escaños; mientras que el partido oficialista - el Partido de la Liberación de Sri Lanka-, pasó a tener 225 escaños, con lo cual posee mayoría en el parlamento. Con dicha mayoría, el gobierno se avoca a enmendar la Constitución del país de suerte de perpetuarse en el poder, a través de reelecciones indefinidas y un Primer Ministro con poder para disolver el parlamento y nombrar directamente jueces y funcionarios anti-corrupción. Es decir, se consolidó el chauvinismo cingalés budista en desmedro de las minorías (entre ellas la tamil) (Ramachandran, 2020). Sin embargo, el país está acuciado por otro grave problema, que es el de estar al borde del default (con importantes calificadoras de riesgo internacional conceptuando al país a la baja) (Ondaatjie y Karunungan, 2021).

En cuanto al tercer elemento, existía una resolución original, a la cual, según la Alta Comisionada Bachelet, Sri Lanka no respondió como debía (dado que, en 2020, Sri Lanka se retiró de la resolución 30/1 del Consejo de Derechos Humanos de las Naciones Unidas, que el gobierno anterior de ese país había co-esponsoreado, para promover la reconciliación, rendición de cuentas y derechos humanos en el país). Ello se suma a un informe lapidario, en enero de 2021, del mismo Consejo, acerca de la situación actual en Sri Lanka, donde se 
hablaba de creciente militarización, marginalización y acoso sobre la sociedad civil y también sobre los medios, que, en febrero de 2021, impulsó al Secretario de Relaciones Exteriores de Sri Lanka a buscar apoyo en la "vecindad". En ese contexto, Rajapaksa le escribió a Modi, solicitándole apoyo en el marco de su planteo de "el vecindario primero". Modi respondió a través de sus voceros, que Sri Lanka debiera hacerse eco de los legítimos reclamos tamiles y además poner en funcionamiento la Enmienda Décimo Tercera de la Constitución, que implica la devolución de poder a las provincias (Senanayake, 2021). Finalmente, sobre Sri Lanka, se dio la Resolución 46/1, del 23 de marzo de 2021, apoyada por 22 votos positivos (entre ellos, los de Argentina, Brasil, México y Uruguay), 11 negativos (donde figuran Bangladesh, China, Pakistán y la Federación Rusa) y 14 abstenciones (por ejemplo, las de la India, Indonesia, Japón y Nepal). Esta resolución considera lo ya señalado (creciente militarización de las instituciones civiles, erosión de la independencia del poder judicial, impunidad de los crímenes, y los derechos humanos, marginalización de las minorías -por ejemplo, en la respuesta a la pandemia se ha constreñido la libertad de religión-, restricciones a la libertad de prensa, etc.) y busca también promover la reconciliación, la asignación de responsabilidades de los crímenes durante la pasada guerra y los derechos humanos. Con ello, se le otorgaron a la Alta Comisionada Bachelet nuevos poderes de investigación sobre los crímenes de guerra, tanto por parte de los Tigres de Liberación Tamil como por parte de las Fuerzas Armadas de Sri Lanka (se estima que hubo alrededor de 80.000 víctimas civiles); se le asignó un importante presupuesto para su tarea, al tiempo que más personal, y se le pidió un informe que debe entregarse en 18 meses, en el cual se debe incluir opciones para la asignación de responsabilidades (Amnesty International, 2021).

Finalmente, entonces, existe, por un lado, la contrafuerza que Tamil Nadu puede hacerle al gobierno central indio acerca de la situación de postergación y agresión de los tamiles en Sri Lanka. Por otro, un poder omnímodo de la familia Rajapaksa que, en confluencia con esos dos elementos, la presión que ejerce Naciones Unidas sobre Sri Lanka, con lo cual sólo queda esperar el desarrollo de las circunstancias, aunque no es difícil prever un panorama complejo y poco esperanzador.

\section{Referencias}

Aljazeera (9 de julio de 2021). Sri Lanka's Rajapaksa family tightens grip with ministerial picks. https://www.aljazeera.com/news/2021/7/9/sri-lankas-rajapaksa-familytightens-grip-with-ministerial-picks 
Amnesty International (23 de marzo de 2021). Press reléase: Sri Lanka: Landmark UN resolution marks crucial turning point on justice and accountability. https://www.amnesty.org/en/latest/press-release/2021/03/sri-lanka-landmark-unresolution-marks-crucial-turning-point-on-justice-and-accountability/

Devotta, N. (2009). The Liberation Tigers of Tamil Eelam and the Lost Quest for Separatism in Sri Lanka. Asian Survey, 49(6),1021-1051. DOI: 10.1525/as.2009.49.6.1021

Ilyas, A. H. (2014). Estate Tamils of Sri Lanka - a socio economic review. International Journal of Sociology and Anthropology, 6(6), 184-191. https://academicjournals.org/journal/IJSA/article-full-text-pdf/88F84BA45633

Ondaatjie, A. y Karunungan, L. (5 de julio de 2021). Markets. Asia's Highest Default Risk Spotlights Sri Lanka Debt Worry. Bloomberg. https://www.bloomberg.com/news/articles/2021-07-05/asia-s-highest-default-riskspotlights-sri-lanka-debt-concerns

Ramachandran, S. (7 de agosto de 2020). Sri Lanka: The Rajapaksas Rise Again. The Diplomat.

Senanayake, H. (2021). Fear of Small Numbers and Political Behaviour of Ethnocentric Majority of Sri Lanka: Undeclared War against Upcountry Tamil Females. Open Political Science, 4, 120-125. https://doi.org/10.1515/openps-2021-0012

The Economic Times (7 de mayo de 2021). Stalin makes his father, party patriarch Karunanidhi's dream come true. https://economictimes.indiatimes.com/news/elections/assembly-elections/tamilnadu/stalin-makes-his-father-party-patriarch-karunanidhis-dream-cometrue/articleshow/82454464.cms 